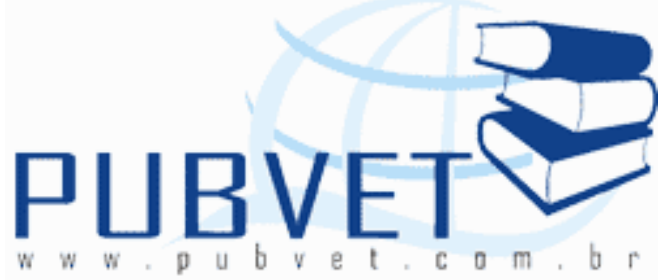

PUBVET, Publicações em Medicina Veterinária e Zootecnia.

\title{
Polimorfismos gênicos responsáveis pela variabilidade na cor de pelagem em ovinos Santa Inês
}

Gleice Rangel Silveira Lima ${ }^{1}$, Celia Raquel Quirino ${ }^{2}$, Aline Pacheco ${ }^{3}$, Julia Gazzoni Jardim ${ }^{1}$

${ }^{1}$ Alunos de Pós graduação do Laboratório de Reprodução e Melhoramento Genético Animal da Universidade Estadual do Norte Fluminense/UENF 2 Professora do Laboratório de Reprodução e Melhoramento Genético Animal da Universidade Estadual do Norte Fluminense/UENF

${ }^{3}$ Bolsista Pós doutoradoCAPES/FAPERJ

Autora: gleice.sil@hotmail.com, cra@uenf.br

\section{Resumo}

Entre os animais domésticos, o ovino é um dos que apresentam mecanismos anatomorfológicos mais propícios à sobrevivência em regiões de altas temperaturas (SANTOS et al., 2006). A cor de pelagem é uma importante característica envolvida na termorregulação. Os principais responsáveis pela ampla variedade de coloração em mamíferos são os genes:Receptor de Melanocortina-1 (MC1R) e a Proteína Sinalizadora de Agouti (ASIP). Ambos apresentam um papel essencial na regulação da síntese de melanina durante o desenvolvimento do pelo (SCHNEIDER, 2013). Este trabalho objetiva o esclarecimento quanto a interação entre genes, os quais revelam regiões polimórficas no genoma de ovinos da raça Santa Inês que estão diretamente 
LIMA, G. R. S., et al. Polimorfismos gênicos responsáveis pela variabilidade na cor de pelagem em ovinos Santa Inês. PUBVET, Londrina, V. 8, N. 23, Ed. 272, Art. 1818, Dezembro, 2014.

ligadas a variabilidade na cor de pelagem e adaptabilidade à temperatura ambiental e ao estresse calórico, refletindo numa melhor produtividade e criação dos ovinos da raça Santa Inês.

\title{
Gene Polymorphisms Responsible For Variability In Color Coat In Santa Inessheep
}

\begin{abstract}
Among domestic animals, the sheep is one of the feature more conducive to survival in regions of high temperatures (SANTOSet al., 2006) anatomorfologic mechanisms. Being the coat color an important feature involved in thermoregulation. Primarily responsible for the wide variety of coloration in mammals are the Melanocortin - 1 Receptor (MC1R) and the Agouti Signaling Protein (ASIP) genes. Both have a crucial role in regulating melanin synthesis during the development (SCHNEIDER, 2013). This work aims to clarify how the interaction between genes, which reveal polymorphic regions in the genome of Santa Ines sheep that are directly linked to variability in coat color and environmental adaptability. Additional studies may explain how these variations occur in order to select animals more adapted to environmental temperature and to heat stress and thus have better productivity and creation of Santa Ines sheep.
\end{abstract}

\section{Introdução}

A ovinocultura está presente em praticamente todos os continentes, essa amplitude se deve principalmente ao poder de adaptação dos ovinos aos diferentes climas, relevos e vegetações. Sendo assim, sua criação é destinada tanto à exploração econômica como à subsistência das famílias de zonas rurais (VIANA, 2008).

A criação brasileira de ovinos é destinada, principalmente, à produção de carne. Dentre as raças criadas no país, destaca-se a raça Santa Inês. Sua 
LIMA, G. R. S., et al. Polimorfismos gênicos responsáveis pela variabilidade na cor de pelagem em ovinos Santa Inês. PUBVET, Londrina, V. 8, N. 23, Ed. 272, Art. 1818, Dezembro, 2014.

origem advém do cruzamento entre ovinos da raça Bergamácia, de origem italiana, com ovelhas crioulas e Morada Nova, seguido de um período de seleção e/ou evolução para ausência de lã. É uma raça com alto potencial para crescimento, mas com baixa taxa de partos múltiplos. Em condições de pastejo, o peso de uma ovelha adulta varia de 40 a $50 \mathrm{~kg}$ e os machos podem atingir até $90 \mathrm{~kg}$ (OLIVEIRA, et al. 2011).

Os ovinos da raça Santa Inês por serem naturalizados no Brasil e provenientes do cruzamento de duas diferentes raças, apresentam variações na cor de pelagem. Entre essas variações destacam-se a cor branca (pelagem totalmente branca, sendo permissível mucosa e cascos brancos), chitada (caracteriza-se por uma pelagem branca com manchas pretas e marrons esparsas por todo corpo), vermelha (pelagem totalmente vermelha) e preta (pelagem totalmente preta) (OLIVEIRA, et al. 2011).

Animais com pelagem escura, geralmente, são mais susceptíveis ao estresse calórico que os de pelagem clara por absorverem maior carga térmica radiante. Embora a reflexão seja maior em uma cor de pelagem clara, para que essa vantagem seja efetiva, a epiderme deve ser pigmentada e os pelos, densamente distribuídos sobre ela (VERISSIMO et al., 2009).

Os ovinos apresentam mecanismos anatomorfológicos propícios à sobrevivência em regiões de altas temperaturas, sendo necessário o conhecimento da tolerância ao calor e da capacidade de adaptação das raças, como forma de embasamento para a exploração ovina, para propostas de introdução de raças em uma nova região ou para nortear um programa de cruzamento (SANTOS, 2006).

Devido à presença das variações da cor de pelagem na raça Santa Inês, torna-se interessante avaliar os efeitos de polimorfismos dos genes que interferem nessa característica fenotípica.Principalmente, devido ao fato da base genética do padrão da cor recessiva da pelagem em ovinos ser ainda pouco compreendida.

A herança da cor de pelagem em mamíferos tem sido estudada principalmente a partir de uma perspectiva qualitativa, onde os fenótipos são 
LIMA, G. R. S., et al. Polimorfismos gênicos responsáveis pela variabilidade na cor de pelagem em ovinos Santa Inês. PUBVET, Londrina, V. 8, N. 23, Ed. 272, Art. 1818, Dezembro, 2014.

definidos por categorias distintas (castanho, preto, marrom, cinza, etc.) e são controlados por poucos genes que mostram uma relação epistática de herança. Entretanto, a variação na cor de pelagem é afetada por um grande número de genes. Por exemplo, foram identificados 127 genes responsáveis pela variação da cor de pelagem em ratos e cerca de 59 desses genes foram relacionados a mutações determinantes dessas variações, sendo recentemente clonados molecularmente (TOTH et al., 2014).

Toth et al. (2014) relataram que as informações genéticas sobre a pigmentação nos pelos dos mamíferos é bastante complexa, exibindo assim características quantitativas e qualitativas. Desta forma, cor de pelagem foi medida por estes pesquisadores através de espectrometria de refletância de acordo com padronização determinada pela Commission Internationale de l'Eclairage.Para a medição objetiva de cor de pelagem, foram utilizadas as variáveis contínuas $L^{*}, a *$ e b*.

Este trabalho teve como objetivo revisar sobre os padrões de cor de pelagem e sobre os genes MC1R e ASIP, os quais revelamregiões polimórficas no genoma de ovinos da raça Santa Inês.

\section{A ovinocultura no Brasil e no mundo}

Os ovinos foram uma das primeiras espécies de animais domesticados pelo homem. A sua criação possibilitava alimento, a partir do consumo da carne, leite e pelo uso da lã, fibra que servia como abrigo contra as variações de temperatura ambiental.

No cenário mundial a ovinocultura é promissora, estimando-se um crescimento anual de 2,1\% durante o período de 2005 a 2014 (FAO, 2007). A Austrália e Nova Zelândia controlam o mercado internacional da carne e lã. No entanto, é esperado queda no número de cordeiros abatidos na Austrália, devido à má condição das pastagens e elevação no preço dos grãos, além disso, o aumento na demanda interna pode diminuir as exportações da Austrália em 7\%. Também é esperado queda na exportação da Nova Zelândia, aumento das importações dos Estados Unidos e estagnação das importações 
LIMA, G. R. S., et al. Polimorfismos gênicos responsáveis pela variabilidade na cor de pelagem em ovinos Santa Inês. PUBVET, Londrina, V. 8, N. 23, Ed. 272, Art. 1818, Dezembro, 2014.

da União Europeia, que continua sendo o destino mais importante da carne ovina (FAO, 2009). Este cenário é favorável a países emergentes na produção e exportação da carne ovina.

Em 2010 o efetivo de ovinos no Brasil foi de 17.380.581 animais, apresentando um aumento de 3,4\% quando comparado a 2009. Dentre as regiões brasileiras o Centro-Oeste apresentou maior crescimento em 2010, com 12,4\%, seguido pela região Norte com 7,1\%, Nordeste com 3,0\%, Sudeste com $2,6 \%$ e Sul com $1,6 \%$. A região Nordeste, apesar de não ter apresentado o maior crescimento em 2010 é a região que possui o maior efetivo de ovinos para produção de carne e leite, com $56,7 \%$ de todo o efetivo nacional. Seus rebanhos começaram a ser explorados economicamente com a introdução de raças especializadas, melhoramento genético e técnicas de manejo que propiciaram a elevação da produtividade nos últimos anos (IBGE, 2010).

A ovinocultura de corte no Brasil possui um alto potencial de crescimento, uma vez que a produção atual não atende a demanda do mercado consumidor, sendo necessária a importação do produto. Isso, devido a diversos fatores que afetam negativamente a estruturação da ovinocultura no Brasil, tais como: o sistema de produção, a escala de produção e constância do fornecimento, o padrão animal, o número de abatedouros e abates clandestinos, preços e importação (REIS, 2009).

O Brasil importa carne ovina, sendo o Uruguai o principal fornecedor, competindo em preço com a carne brasileira e ainda é rotulada como carne especial, de qualidade superior. Essa competitividade da carne ovina importada afeta os preços pagos ao produtor, além disso, possuem uma maior aceitação dos consumidores em relação à carne ovina brasileira (VIANA, 2008).

Atualmente o consumo de carne ovina per capta no Brasil é de, aproximadamente $0,7 \mathrm{~kg}$, sendo baixo quando comparado ao consumo de carne bovina, $36,5 \mathrm{~kg}$, de frango, $29,9 \mathrm{~kg}$ e suína, $10,5 \mathrm{~kg}$ (FAO, 2007).

Desafios atuais da ovinocultura de corte no Brasil seriam disponibilizar uma ampla variedade de cortes para que todas as classes sociais 
LIMA, G. R. S., et al. Polimorfismos gênicos responsáveis pela variabilidade na cor de pelagem em ovinos Santa Inês. PUBVET, Londrina, V. 8, N. 23, Ed. 272, Art. 1818, Dezembro, 2014.

tenham acesso à carne ovina, estratégias de marketing e melhorar a estruturação da ovinocultura, através da organização dos produtores e aplicação de sistemas de produção viáveis, fornecendo carne de qualidade aos consumidores (MACEDO et al., 2000).

\section{Padrões de pelagem da raça Santa Inês}

Segundo Santos (2007), a raça Santa Inês possui dois tipos de pelagens básicas que incluem todas as possíveis variações:

a) Monocolorida ou coloração única: varia desde a branca-suja à negra. Nos dias atuais destacam-se a coloração "pelo-de-boi" (ou castanha), a vermelha e a negra. Alguns já começam a selecionar animais de pelagem mais branca, com preferencia para os que apresentem mucosas, olhos, cascos, pavilhão e bordas auriculares de coloração escura;

b) Multicolorida: com manchas escuras sobre um fundo claro, mas também são comuns animais com fundo escuro e manchas claras. Podem ser agrupadas em quatro subvariações:

- Malhada: manchas arredondadas, grandes e nítidas;

- Tartarugada: manchas arredondadas, pequenas com bordas definidas ou não;

- Lavrada: manchas retas ou muito definidas;

- Chitada: pingos, borrões, sem contornos definidos;

- Chuviscada: pingos, salpicos, chuviscos, com contorno definidos.

Características de pelame como a cor, devem ser levadas em consideração na avaliação da tolerância ao calor, uma vez que animais com pelame escuro absorvem maior radiação solar, resultando em maior estresse para estes animais do que os de pelame claro. Muitas vezes, as mudanças nos padrões de comportamento, como a agitação e intolerância, são exemplos de reflexos da tentativa do animal de amenizar, fugir ou escapar de agentes/estímulos estressantes (SANTOS et al., 2011).

Em regiões tropicais (quentes), o ovino apresenta pele fina coberta por pelos sedosos e finos, uma vez que produzem pouco calor corporal. A 
LIMA, G. R. S., et al. Polimorfismos gênicos responsáveis pela variabilidade na cor de pelagem em ovinos Santa Inês. PUBVET, Londrina, V. 8, N. 23, Ed. 272, Art. 1818, Dezembro, 2014.

coloração da pele é determinada pela quantidade de pigmentos de melanina. A coloração negra da pele garante a defesa contra os raios actínicos (ultravioletas). A coloração clara da pele garante uma melhor resistência ao frio. Assim, nas regiões tropicais os animais precisam ter uma pele muito pigmentada, com muitas glândulas sebáceas, pois a oleosidade da pele funciona como um filtro contra as radiações solares (OLIVEIRA et al., 2011).

Uma das virtudes da raça Santa Inês é poder ser criada em qualquer situação, tendo em vista que sua pelagem diversificada é uma riqueza em seu arsenal biológico. Assim, cada região, clima, altitude, exige uma pelagem e uma pele adequada. A pele e a pelagem são duas importantes ferramentas de sobrevivência diante da adaptabilidade térmica do animal ao ambiente, permitindo ser criada em qualquer ambiente, devido a esta versatilidade de sua pelagem (SANTOS, 2007).

\section{Adaptabilidade térmica}

A tolerância ao calor e a adaptabilidade a ambientes tropicais são fatores muito importantes na criação e produção de ovinos. O aumento da temperatura ambiente é fator desencadeante do estresse calórico, que acarreta aumento da secreção do hormônio cortisol, provocando uma série de efeitos no metabolismo do animal que alteram o seu comportamento e bemestar. Esses fatores provocam prejuízos em relação à ingestão e digestão de alimentos e alteração da taxa metabólica dos animais. Isto pode afetar negativamente o desempenho e a função reprodutiva (VERISSIMO et al., 2009).

O animal, nas condições tropicais adversas deve apresentar características compatíveis com as condições ambientais a fim de expressar todo o seu potencial genético. A cor de pelagem é uma importante característica envolvida na termorregulação, além dos parâmetros fisiológicos dos animais, sendo assim viável o seu uso no processo de seleção dos animais para clima tropical (NEVES, 2008). 
LIMA, G. R. S., et al. Polimorfismos gênicos responsáveis pela variabilidade na cor de pelagem em ovinos Santa Inês. PUBVET, Londrina, V. 8, N. 23, Ed. 272, Art. 1818, Dezembro, 2014.

Animais com pelagem escura, geralmente, são mais susceptíveis ao estresse calórico que os de pelagem clara por absorverem maior carga térmica por radiação solar. Embora a reflexão seja maior em uma capa de coloração clara, para que essa vantagem seja efetiva, a epiderme deve ser pigmentada e os pelos densamente distribuídos sobre ela (VERISSIMO et al., 2009).

A mensuração da tolerância ao calor,pode ser baseada na temperatura corporal do animal, desta forma, esta temperatura seria um demonstrativo relevante para o índice de estresse calórico, onde o mesmo é um importante fator que limita o desenvolvimento dos ovinos e a expressão do seu potencial genético produtivo. As limitações à produção em áreas tropicais podem ser ocasionadas por elementos ambientais estressantes, tais como: temperatura do ambiente, umidade do ar, radiação do solar aos trópicos e a sobrevivência em condições difíceis, como muitas doenças e escassez de alimentos. Estes fatores somados ao estresse ambiental, causa diminuição das taxas de sobrevivência e crescimento e da eficiência reprodutiva.

Segundo Quesada et al. (2001), a produtividade animal depende da capacidade do animal manter a temperatura corporal. Os animais utilizam vários mecanismos para manter a homeotermia, como a vasodilatação periférica, onde há o redirecionamento do fluxo sanguíneo para a superfície corporal, aumentando a temperatura da superfície do animal facilitando a dissipação de calor por mecanismos não evaporativos (condução, convecção e radiação). Entretanto, a eficácia desses mecanismos depende do gradiente térmico entre o corpo do animal e o ambiente. Quanto maior o gradiente maior será a dissipação de calor. A pele mais quente do animal tende a perder calor em contato com o ar mais frio. Se a temperatura do ar aumenta, diminui essa perda de calor por meio do calor sensível, aumentando a temperatura do núcleo central, assim, o organismo animal através de mecanismos evaporativos, como a sudorese e/ou frequência respiratória, aumenta a dissipação de calor insensível. A forma insensível de dissipação de calor é regulada pela umidade, ou seja, quanto maior a umidade ambiental mais será comprometido esse mecanismo de dissipação. 
LIMA, G. R. S., et al. Polimorfismos gênicos responsáveis pela variabilidade na cor de pelagem em ovinos Santa Inês. PUBVET, Londrina, V. 8, N. 23, Ed. 272, Art. 1818, Dezembro, 2014.

Todavia, a temperatura do ar e a umidade são consideradas como os principais elementos climáticos responsáveis pelo incremento calórico à temperatura corporal dos animais. Se o animal não conseguir dissipar calor excedente através dos mecanismos citados, a temperatura retal aumenta acima dos valores fisiológicos normais e desenvolve-se o estresse calórico, responsável em parte pela baixa produtividade animal nos trópicos (FILHO et al., 2011).

Santos (2006) relata em seu trabalho que a avaliação de uma raça ou grupo genético não pode ser baseada apenas na capacidade de ganho de peso e no rendimento de carcaça, mas também na eficiência produtiva, adaptabilidade, prolificidade e taxa de sobrevivência. Assim, se a performance produtiva for baseada apenas no desempenho produtivo, pode estar sujeita a erros. Os critérios de tolerância, longevidade e adaptação dos animais são determinados pelas medidas fisiológicas da respiração, frequência cardíaca e temperatura corporal.

Para Brown-Brandl et al. (2003), a temperatura retal e a frequência respiratória são consideradas as melhores variáveis fisiológicas para estimar a tolerância de animais ao calor e em menor escala tem sido objeto de estudo a frequência cardíaca, temperatura da pele e os constituintes sanguíneos.

A frequência cardíaca e respiratória são variáveis sujeitas a um grande número de variações devido a fatores como a temperatura ambiente, como a idade, a individualidade, o temperamento e o grau de excitação do animal. Entretanto, essas frequências são parâmetros altamente significativos quanto a mensuração para verificação da adaptabilidade do animal ao estresse calórico (SANTOS, 2006).

Desta forma, o estudo da adaptabilidade ambiental em ovinos é importante para a determinação de fenótipos mais adequados à condição ambiental específica visando a obtenção de uma melhor produtividade.

\section{Genética Molecular e genes responsáveis pela cor de pelagem}


LIMA, G. R. S., et al. Polimorfismos gênicos responsáveis pela variabilidade na cor de pelagem em ovinos Santa Inês. PUBVET, Londrina, V. 8, N. 23, Ed. 272, Art. 1818, Dezembro, 2014.

Várias têm sido as contribuições da genética molecular na produção ovina ao redor do mundo. Marcadores moleculares e genes de efeito maior têm sido identificados, relacionados à maior deposição de músculos, maior prolificidade e a resistência aos parasitos (BARRETT, 2012).

As características de qualidade da carne ovina têm sido objeto de intensos estudos fora do Brasil. A maciez, cor, aroma, sabor e marmoreio da carne são estudadas também sob o ponto de vista genético. A diversidade das aptidões dos ovinos também podem ser observadas em relação às características reprodutivas.

As análises fenotípicas podem ser facilitadas a partir da identificação direta de genótipos, baseado em marcadores moleculares que segregam juntamente com os genes de interesse (BOREM, 2009) .

Desta forma, os marcadores moleculares são uma ferramenta, que podem auxiliar o melhoramento animal, destacando a seleção assistida por marcador molecular para características qualitativas, verificação de parentesco e diagnóstico de anomalias hereditárias.

Cor de pelagem em mamíferos depende, basicamente, da quantidade relativa dos dois tipos básicos de tirosina derivada de melanina: eumelanina (coloração escura) e feomelanina (coloração clara) (ROYO et al., 2008).

Dos diversos locos gênicos envolvidos na pigmentação, dois deles são os principais responsáveis pela ampla variedade de coloração em mamíferos: o Receptor de Melanocortina-1 (MC1R) e a Proteína Sinalizadora de Agouti $(A S I P)$, os quais eram originalmente conhecidos como agouti e extension quando identificados por estudos com camundongos. Ambos apresentam um papel essencial na regulação da síntese de melanina durante o desenvolvimento do pelo (SCHNEIDER, 2013).

A coloração preta da pelagem em ovelhas é dominante e tem sido relatada por uma extensão alélica, transportando o p.M73K e p.D121, que indica alterações na sequência de codificação do gene MC1R (ROYO et al., 2008). 
LIMA, G. R. S., et al. Polimorfismos gênicos responsáveis pela variabilidade na cor de pelagem em ovinos Santa Inês. PUBVET, Londrina, V. 8, N. 23, Ed. 272, Art. 1818, Dezembro, 2014.

A variabilidade da cor de pelagem é influenciado pelos genes MC1R e ASIP, cujos produtos interagem na regulação da produção de melanina. Foi relatado por Schneider (2013) que os fenótipos melânicos em camundongos frequentemente se devem a mutações dominantes associadas com a proteína MC1R super ou constitutivamente ativa ou a mutações de herança recessiva causando a perda parcial ou total da função da proteína ASIP. Ou seja, exacerbação da função do MC1R ou perda da função do ASIP induzem o melanismo.

Royo et al. (2008) relatam a ligação entre a pigmentação recessiva na cor de pelagem com os marcadores de DNA do cromossomo 13 em ovinos, em que os mapas do locus agouti, indicam o gene ASIP como um candidato para a pigmentação recessiva em ovelhas.

Outra forma de estudar a cor de pelagem seria como característica quantitativa. Toth et al. (2014), sugerem que a cor de pelagem seria determinada por vários genes de pequeno efeito. Para a medição objetiva de cor de pelagem, utilizaram as variáveis contínuas $L^{*}$, a* e b*. O valor de $L^{*}$ indica a luminosidade e está relacionado com a refletância luminosa (quantidade de luz refletida ponderada com a resposta espectral do olho humano); a* mede a saturação da cor vermelha para o verde; b* mede a saturação da cor amarelo para o azul.

Desta forma, o estudo das variações da cor de pelagem em ovinos Santa Inês seria abordado não apenas como característica qualitativa, mas também como característicaquantitativa possibilitando assim, melhor avaliaçãos sobre suas variações.

\section{Receptor de Melanocortina-1 (MC1R)}

$O$ gene MC1R codifica um receptor acoplado a proteína $G$ contendo sete hélices transmembrana, que é expresso em melanócitos da pele, folículos pilosos e em células do sistema imune. Ao se ligar ao hormônio estimulante de melanócito (a-MSH), o MC1R ativa a síntese de AMP cíclico (cAMP) intracelular induzindo a síntese de eumelanina (pigmento escuro: preto, marrom). A 
LIMA, G. R. S., et al. Polimorfismos gênicos responsáveis pela variabilidade na cor de pelagem em ovinos Santa Inês. PUBVET, Londrina, V. 8, N. 23, Ed. 272, Art. 1818, Dezembro, 2014.

ativação do MC1R é inibida pelo gene ASIP, que impede sua ativação pelo aMSH e, assim, induz a troca da síntese de eumelanina para feomelanina (pigmento claro: amarelo, avermelhado) (BARRETT, 2012).

Ganhos e perdas de funções devido às mutações do gene MC1R como determinantes de dominância para cor de pelagem preta/escuro e determinantes de recessividade para cor de pelagem amarela ou parcialmente recessivo para cor vermelho/branco, têm sido descritos num grande número de mamíferos, como por exemplo, ratos, humanos, gado, suínos, cavalos, cães, gatos, coelhos e caprinos (FONTANESI et al., 2009).

Em ovinos, estudos genéticos identificaram na raça Missense em regiões da Toscana e Emilia Romagna, na Itália, dois alelos causados por duas mutações no gene MC1R (p.M73K e p.D121N) que também estão presente nas raças Dala noruegues, Corriedale, Damara, Preto Merino, Black Castellana e Karakul e o tipo selvagem (E1) que é um alelo amplamente distribuído na maioria das raças. Outra mutação no gene MC1R (p.R67C) na raça Valle del Belice também foi descrita (FONTANESI, 2010).

\section{Proteína Sinalizadora de Agouti (ASIP)}

O ASIP é um peptídeo parácrino produzido no folículo piloso e que se comporta como antagonista ao MC1R, impedindo sua ativação e induzindo a troca da síntese de eumelanina para feomelanina (pigmento claro: amarelo, avermelhado).

A região codificadora do gene do ASIP é determinada por três exons $(2,3$ e 4). A sequência da proteína ASIP contém um sinal de secreção, com um básico domínio amino-terminal, um estiramento de prolina e uma cisteína, formando um domínio carboxi-terminal que se dobra em uma estrutura de nó característico. O domínio rico em cisteína é responsável pela atividade de ligação in vitro da melanocortina. Um grande número de alelos foram descritos no locus agouti em camundongos, onde a maioria tem sido caracterizada pelo nível de DNA (BARRETT, 2012). 
LIMA, G. R. S., et al. Polimorfismos gênicos responsáveis pela variabilidade na cor de pelagem em ovinos Santa Inês. PUBVET, Londrina, V. 8, N. 23, Ed. 272, Art. 1818, Dezembro, 2014.

Em ovinos, no mínimo, três mutações foram sugeridas para exclarecer a cor não-agouti (clara) recessivo para cor de pelagem preta: a deleção de 5 pb do exon 2 (g.100 - 105delAGGAA); uma mutação na raça Missense no exon 4 (g.5172T.A ou p.C126S ) foi descrita por Fontanesi (2010); e uma deleção de 9 pb no exon 2 ( .10 - 19delAGCCGCCTC), restando apenas 10 pb após o códon de iniciação ATG, o que iria resultar na perda de um tripéptideo podendo prejudicar parcialmente a função ASIP (BARRETT, 2012). Além disso, a variação do número de cópias de uma grande região do genoma incluindo o gene ASIP em ovinos tem mostrado ser a causa genética da coloração branca da pelagem de forma dominante (FONTANESI, 2010).

\section{Considerações finais}

A adaptabilidade de ovinos da raça Santa Inês, assim como a sua tolerância a temperatura são fatores importantes à produção e criação desses animais, uma vez que a cor de pelagem influência diretamente no estresse térmico.

Os genes MC1R e ASIP estão diretamente envolvidos nas variações de cor de pelagem e desta forma, seus estudos podem esclarecer como essas variações ocorrem com objetivo de selecionar animais mais resistentes e adaptados a temperatura nos trópicos, podendo assim obter uma melhor produtividade da raça.

\section{ReferênciasBibliográficas}

BARRETT R. D. H. Bad coat, ripped genes: cryptic selection on coat colour varies with ontogeny in Soay sheep. Department of Organismic and Evolutionary Biology, Harvard University, Cambridge, MA 02138, USA Molecular Ecology (2012) 21, 2833-2835.

BOREM A., CAIXETA E.T.. Marcadores Moleculares. Universidade Federal de Viçosa: 2009. Viçosa-MG: 2 ed.

BROWN-BRANDL T. M., NIENABER J. A., EIGENBERG R. A..Thermoregulatory responses of feeder cattle.Journalof Thermal Biology, v. 28, p. 149-157, 2003. 
LIMA, G. R. S., et al. Polimorfismos gênicos responsáveis pela variabilidade na cor de pelagem em ovinos Santa Inês. PUBVET, Londrina, V. 8, N. 23, Ed. 272, Art. 1818, Dezembro, 2014.

FILHO A. E., TEODORO S. M., CHAVES M. A., SANTOS P. E., FERREIRA D., SILVA1 M. W. R., MURTA R. M., CARVALHO G. G. P., SOUZA L. E. B.. Zona de conforto térmico de ovinos da raça Santa Inês com base nas respostas

fisiológicas. Rev. Bras. Zootec., v.40, n.8, p.1807-1814, 2011.

FONTANESI L., RUSTEMP A., BRKAB M., RUSSO V.. Analysis of polymorphisms in the agouti signalling protein (ASIP) and melanocortin 1 receptor (MC1R) genes and association with coat colours in two Pramenka sheep types.Small Ruminant Research105 (2012) 89- 96.

FONTANESI L., DALL'OLIO S., BERETTI F., PORTOLANO B., RUSSO V..Coat colours in the Massese sheep breed are associated with mutations in the agouti signalling protein (ASIP) and melanocortin 1 receptor (MC1R) genes. Sezione di Allevamenti Zootecnici, University of Bologna. July, 2010.

instituto bRASILEIRO De Geografia e eStatísticA - IBGE. Produção da pecuária municipal. Rio de Janeiro, v. 38, 2010. Disponível em: http://www.iepec.com/noticia/ovinocultura-de-corte-no-brasil-e-nomundo: Acesso em: 10/03/2013.

MACEDO, A.F.; SIQUEIRA, E.R.; MARTINS, E.N. Análise econômica da produção de carne de cordeiros sob dois sistemas de terminação: pastagem e confinamento. Ciência Rural, Santa Maria, v. 30, n.4, p.677-680, 2000.

NEVES M. L., MENEZES W.. Índices de conforto térmico para ovinos Santa Inês de diferentes cores de pelame em condições de pastejo. Dissertação (Mestrado em Zootecnia - Área: Produção Animal) - Universidade Federal Rural de Pernambuco. Departamento de Zootecnia. Orientador : Marcílio de Azevedo. 2008.

OLIVEIRA R. V., XIMENES F. H. B., MENDES C. Q., FIGUEIREDO C.R. R., F. PASSOS. Manual de Criação de Caprinos e Ovinos. CODEVASF. Brasília-DF: 2011.

ORGANIZAÇÃO DAS NAÇÕES UNIDAS PARA A AGRICULTURA E ALIMENTAÇÃO - FAO. Estatísticas FAO. 2007. Disponível em: www.fao.org. Acesso em: 20/02/2013.

ORGANIZAÇÃO DAS NAÇÕES UNIDAS PARA A AGRICULTURA E ALIMENTAÇÃO - FAO. Estatísticas FAO - Meat and meat products. 2009. Disponível em: www.fao.org. Acesso em: 20/02/2013.

QUESADA M., MCMANUS C., COUTO F. A. D.Tolerância ao calor de duas raças de ovinos deslanados no Distrito Federal. Rev. Bras. Zootec., 30(3):10211026, 2001. 
LIMA, G. R. S., et al. Polimorfismos gênicos responsáveis pela variabilidade na cor de pelagem em ovinos Santa Inês. PUBVET, Londrina, V. 8, N. 23, Ed. 272, Art. 1818, Dezembro, 2014.

REIS, F.A. Atualidades na criação de ovinos no Brasil Central. In: CONGRESSO INTERNACIONAL FEINCO, 5., 2009, São Paulo: FEINCO, 2009. p.1-14.

ROYO L. J., A' LVAREZ I., ARRANZ J. J., FERNA'NDEZ I., RODRI'GUEZ A., PE'REZ-PARDAL L., GOYACHE F..Differences in the expression of the ASIP gene are involved in the recessive black coat colour pattern in sheep: evidence from the rare Xalda sheep breed. Animal Genetics, 39, 290-293, 2009.

SANTOS J. R. S., SOUZA B. B., SOUZA W. H., CEZAR M. F., TAVARES G. P.. Physiologic responses and thermal variation of Santa Inês, Morada Nova sheep and their crossbreed with Dorper breed to the semi-arid northeastern of Brazil.Ciênc. agrotec., Lavras, v. 30, n. 5, p. 995-1001, set./out., 2006.

SANTOS, R. Santa Inês: a raça fundamental. Editora Agropecuária Tropical Ltda: 2007. Uberaba-MG

SANTOS M. M., AZEVEdo M., COSTA L. A. B., FILHO F. P. S., MODESTO E. C., LANA A. M. Q., Comportamento de ovinos da raça Santa Inês, de diferentes pelagens, em pastejo. Acta Scientiarum. Animal Sciences. Maringá, v. 33, n. 3, p. 287-294, 2011.

\section{SCHNEIDER A.. Investigação da base molecular e história evolutiva do}

Melanismo em felídeos selvagens. Pontifícia Universidade Católica do Rio Grande do Sul Faculdade de Biociências - Programa de Pós-Graduação em Biologia Celular e Molecular. Porto Alegre, 2013.

TOTH Z., KAPS M., LKNER SO J., BODO I., CURIK I..Quantitative genetic aspects of coat color in horses. Journal of animal science. February, 2014.

VERÍSSIMO C. J., TITTO C. G., KATIKI L. M., BUENO M. S., CUNHA, E. A., MOURÃO G. B., OTSUK I. P., PEREIRA A. M. F., FILHO J. C. M., TITTO E. A. L.. Tolerância ao calor em ovelhas Santa Inês de pelagem clara e escura.

Rev. Brasileira Saúde e Produção Animal,v.10, n.1, p.159-167, jan/mar, 2009.

VIANA, J.G.A. Panorama Geral da Ovinocultura no Mundo e no Brasil. Revista Ovinos, Porto Alegre, ano 4, n.12, 2008. 